\title{
Mrth \\ LA PAOTECCIÓN EXTENSIVA DE LA JURISPRUDENCIA CONSTITUCIONAL DE MUJERES CON VIH/SIDA: \\ GESTANTES Y TRABAJADORAS SEXUALES
}

\section{RESUMEN}

A partir de la identificación del precedente jurisprudencial emanado de la Corte Constitucional, frente al amparo de la salud de personas que padecen el Síndrome de Inmuno Deficiencia Adquirida (SIDA) y/o son portadores del Virus de Inmunodeficiencia Humana (VIH), se identifican los criterios adoptados por la Corte encaminados a garantizarle a ese segmento de la población la protección en materia de salud, teniendo en cuenta que esta no se consideró como derecho fundamental en la Carta Política colombiana - sin embargo, asumiendo la Corte Constitucional el papel de garante en su protección, desde sus primeros pronunciamientos, determina el alcance y contenido de forma diferente en relación con la época del fallo.

De lo anterior se colige el desarrollo extensivo en la protección constitucional a la salud, ya que se vino amparando en el Artículo 13 de la Constitución el cual evoca el derecho a la igualdad, verbi gracia, el fundamento jurídico de los primeros fallos de revisión de tutelas, estuvo amparado en ese derecho, en el acceso a servicios de salud y posteriormente fue sustentado en la protección del derecho social a la salud en conexidad con el derecho fundamental a la vida, para que en los últimos fallos se determinara que la salud siempre ha sido un derecho fundamental autónomo, en cuanto no requiere de la conexidad con derecho fundamental alguno, para ser salvaguardado judicialmente desde los fallos de tutela, sino que debe ampararse directamente como un derecho fundamental independiente.

Dicha protección se ve reforzada frente a la población en condiciones especiales de vulnerabilidad, grupo dentro del cual se encuentran las mujeres gestantes y trabajadoras sexuales, respecto

\section{Dannia Estefani López Cruz*}

*Auxiliar de investigación - Semillero de Investigación GEA- Línea Investigativa de Derecho Constitucional - Grupo de Investigación Jurídica y Social - Derecho y Ciencias Políticas - Universidad de Boyacá - Tunja. (Contacto: danlopez@uniboyaca.edu.co)

Fecha de recepción: marzo 25 del 2015. Fecha de aceptación: mayo 29 del 2015

de las quienes, los criterios jurisprudenciales han enfatizado en la doble garantía de acceso eficaz a los servicios de salud, ampliando dicha protección y precisando el alcance de este derecho fundamental, así como los lineamientos en la prestación del servicio y el acceso a los respectivos tratamientos posteriores.

Palabras Clave: Corte Constitucional, derecho, salud, VIH/SIDA, vulnerabilidad, mujeres gestantes, trabajadoras sexuales. 


\title{
THE EXTENSIVE PROTECTION OF CONSTITUTIONAL JURISPRUDENCE OF WOMEN
} WITH HIV I MIOS: PREGNANT WOMEN AND SEX WORKEBS

\begin{abstract}
Citar este artículo así

López, D. (2016). La protección extensiva de la jurisprudencia constitucional de mujeres con VIH/Sida: gestantes y trabajadoras sexuales. Justicia, Sociedad y Derecho, 1(1), 66-87.

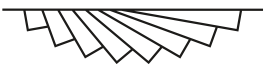

Keywords: Constitutional Court, right, health, HIV/AIDS, vulnerability, pregnant women, sex workers.

Since the identification of the jurisprudence precedent issued by the Constitutional Court regarding the health of people suffering from Acquired Immune Deficiency Syndrome (AIDS) and / or carriers of the Human Immunodeficiency Virus (HIV), it can be identified the criteria adopted by the Court. It guarantees that segment of the population the protection in health, considering that this was not taken as a fundamental right in the Colombian Political Constitution. However, the Constitutional Court, assuming the role of guarantors of their protection, from its first pronouncements, determines the scope and content differently, in relation to the decision time of failure.

As stated above, it can be inferred the extensive development in the constitutional protection of health, since it is included in Article 13 of the Constitution, which evokes the right to equality; for example, the legal basis of the first verdicts of guardianships review was protected by that right. Also, access to health services and subsequently the protection of the social right to health in connectedness with the fundamental right to life, so that in the last verdicts it is determined that health has always been an autonomous fundamental right, as it does not require connectedness with any fundamental right in order to be judicially safeguarded in the verdicts of guardianship, but it must be directly protected as an independent fundamental right.

That protection is reinforced for the population in special conditions of vulnerability, group in which pregnant women and sex workers are included, people in which the legal criteria has emphasized the double guarantee on effective access to health services, extending such protection and specifying the scope of this fundamental right, as well as the guidelines in service delivery and access to the respective subsequent treatments.
\end{abstract}




\section{INTRODUCCIÓN}

A partir de la Constitución colombiana de 1991 y debido a su cambio normativo, dado por la concepción de un Estado Social de Derecho y otorgando primacía al sentido social, por el cual deberían ser impulsadas todas las actuaciones estatales y ciudadanas, pero sobre todo con el establecimiento de los pilares en los que se apoya la Carta como son el respeto de la dignidad humana, el trabajo, la solidaridad y en la prevalencia del interés general sobre el interés particular, permitiendo así el reconocimiento de una serie de derechos inalienables a la existencia de la persona humana. Lo anterior originó que debido a su imprescindibilidad para la garantía de las condiciones mínimas para su supervivencia, se establecieran los derechos denominados como fundamentales.

En ese orden de ideas se establecieron herramientas para que los ciudadanos acudieran a la administración de justicia para que esta les garantizara el goce individual de dichos derechos, determinándose como instrumento protector especial la acción de tutela. Por su parte la salud, que de manera fáctica se convertía en un derecho fundamental, no fue contemplada dentro de dicho grupo de derechos, sino que se catalogó como un derecho social, además de un servicio obligatorio del Estado.

Esta condición permitió que en el desarrollo jurisprudencial de la Corte, durante las dos primeras décadas desde 1991 a 2011, en la revisión de fallos de tutela por el alto tribunal constitucional, se modificaran los criterios fundamentadores de la salud, ya no solo como un derecho social, sino como un derecho fundamental debido a su conexidad íntima con la vida, muy a pesar de no encontrarse catalogado directamente como derecho fundamental, habilitando jurídicamente a la acción de tutela como el mecanismo idóneo para la reclamación de atención en salud porque a falta de esta se pone en riesgo la vida.

Con la expedición de la normativa reglamentaria del precepto constitucional referente a la salud (Ley 100, 1993), Decretos reglamentarios e interpretaciones jurisprudenciales, la 
salud se define como el mantenimiento de las condiciones normales del ser humano para su funcionalidad física y mental, conllevando el acceso a las medidas necesarias que restablezcan las condiciones óptimas ante cualquier perturbación de la salud (Corte Constitucional, Sala Tercera de Revisión, Sentencia de Tutela 597, 1993) y que el tratamiento del derecho a la salud, en caso de enfermedades "catastróficas y de alto costo", como la portabilidad del virus de inmunodeficiencia humana $(\mathrm{VIH})$ y el padecimiento del Síndrome de Inmuno Deficiencia Adquirida ${ }^{1}$ (Sida)², no podía ser reconocido como a pacientes de otras clases de enfermedades, aun cuando estas fueran más graves, por el contrario, debían establecerse prerrogativas específicas para los pacientes que padecieran este tipo de enfermedad, teniendo en cuenta que las repercusiones físicas de estos pacientes, los costos de asistencia médica, las altas tasas de mortalidad, la inexistencia de tratamiento curativo salvo algunos paliativos, entre otras causas, ponen a quienes las padecen en situación de alta vulnerabilidad física y social, frente a la exigencia de sus derechos (OMS, 2014).

\footnotetext{
1 En términos de la Organización Mundial de la Salud (OMS), autoridad directiva y coordinadora de la acción sanitaria de las Naciones Unidas, el VIH es un virus de transmisión sanguínea o sexual, que luego de su incubación en el organismo por varios años, se expresa con la destrucción de las células que realizan la función inmunitaria, modificando su función, de forma que la persona se hace vulnerable, ante la ineptitud de su sistema de barrera, haciéndose inmuno deficiente, degenerado en el SIDA, síndrome que provoca una mayor sensibilidad a infecciones y enfermedades, definiéndose con la aparición de ciertos tipos de cáncer, infecciones u otras manifestaciones clínicas graves.

2 La Corte Constitucional otorga igual tratamiento jurídico tanto en la fase de incubación del virus (VIH) como de los efectos patológicos infecciosos posteriores de la enfermedad (Sida).
}

Con ello y especialmente cuando coinciden en el mismo grupo, circunstancias que acreditan condiciones especiales de vulnerabilidad, el alto Tribunal ha determinado que tratándose de personas en condiciones especiales de vulnerabilidad -entendidas por la imposición de barreras externas a un individuo, ya sean de tipo social, cultural y/o económico, las cuales logran coartar los ideales de progreso en el desarrollo individual y de subsistencia, incluyendo el bienestar del núcleo familiar, impidiendo alcanzar niveles más altos de bienestar- por cuanto esta condición lo pone en mayor riesgo de estar expuesto a sinnúmero de desventajas - (Corte Constitucional, Sala Séptima de Revisión. Sentencia de Tutela 244, 2012) se consideran individuos de atención especial o prevalente para el goce y garantía de sus derechos.

Partiendo de estas premisas, se considera que existen diversos grupos de personas que pueden calificarse con condiciones especiales de vulnerabilidad, dentro de los cuales se encuentra la población femenina, que puede verse atacada en múltiples escenarios, especialmente en el ámbito de la salud, y de la misma manera resaltan dos subgrupos en la población femenina que padecen de la enfermedad mencionada y que debido a la particularidad de sus necesidades y riesgos médicos, resultan ser los siguientes grupos de interés: mujeres gestantes y trabajadoras sexuales VIH/Sida positivas que por sus condiciones fácticas particulares, requieren una mayor atención en cuanto a garantizarles el acceso a los tratamientos genéricos aplicables, además de prerrogativas acordes a la necesidad de estas. Para citar un ejemplo, para la madre gestante además de los cuidados para ella, se 
tendrían los cuidados preventivos del contagio del virus hacia el nasciturus, como titular del derecho a la salud, situación que redunda en la determinación del no contagio del que está por nacer.

Ahora bien, de conformidad con la imperativa necesidad de que el acceso a la salud no estuviese obstruida por limitantes de cualquier tipo y tratándose del género femenino que en determinado momento podría considerarse objeto de discriminación en cuanto a su acceso a los servicios de salud, máxime cuando se desempeñan como trabajadoras sexuales, de tal suerte que las reclamaciones de tipo administrativo tampoco pueden ser obstáculos para el acceso y la cobertura de los tratamientos de medicina preventiva acerca del contagio y retroceso del desarrollo del síndrome.

Es por ello que se debe analizar referente a los extremos de la línea jurisprudencial de la Corte en materia de salud, si estos son de tendencia extensivo o restrictivo para mujeres que padeciendo VIH/SIDA pueden ser clasificadas además dentro de la población en condiciones especiales de vulnerabilidad-gestantes y trabajadoras sexuales-, estableciendo materialmente su extensión, en los aspectos más importantes.

Para esto, se realizó investigación de enfoque cualitativo de carácter descriptivo, empleando un diseño de tipo compuesto, debido a la conjugación de dos modalidades: el estudio de caso, por cuanto la selección de las decisiones por analizar se delimita al ajuste de sujetos - mujeres -en condiciones especiales de vulnerabilidad, donde se seleccionaron dos grupos, teniendo en cuenta sus situaciones de trascendencia social, que determinan su protección de prioridad, y de otra parte por los altos niveles de discriminación; y la teoría fundamentada al caracterizar las decisiones adoptadas por la Corte Constitucional en la extensión del derecho a la salud de los grupos seleccionados.

Asimismo, se emplearon las herramientas propuestas por López (2001) para la construcción de líneas jurisprudenciales. En primera medida se identificó la sentencia arquimédica para uno de los grupos, posteriormente el nicho citacional, del cual se seleccionaron las sentencias hito, para finalmente hallar la sentencia fundadora de línea; no obstante en la construcción del nicho y las sentencias hito, que comprendió 20 años de jurisprudencia constitucional, metodológicamente se fraccionaron los fallos dependiendo el año de su emisión en cuatro bloques (2011-2006 / 2005-2000 / 1999-1996 / 1995 - 1991), los cuales servirán para presentar el comportamiento del precedente del criterio constitucional en la materia investigada.

Con respecto a la revisión de las sentencias hito se determina que en términos generales, la Corte siempre ha encontrado en el derecho a la salud un aspecto digno de reconocimiento debido a sus impli caciones con el bienestar y dignidad del individuo, y aún más tratándose de las enfermedades que su época denominó "mortales", de ahí que aunque sus pronunciamientos estuviesen limitados en la timidez y precisión, los pacientes contagiados de $\mathrm{VIH}$ o que ya padeciesen el SIDA, que por medio de la acción de tutela acudieron a solicitar el amparo de sus derechos encontraron respuesta afirmativa, sin embargo, no con fundamento en el derecho a la salud, sino 
que de conformidad a la riguridad de la acción constitucional regulada en su normativa reglamentaria (Decreto n. 2591, 1991).

Dicho Decreto exigía la protección de uno de los derechos taxativamente contenidos dentro del acápite de DERECHOS FUNDAMENTALES de la Constitución Política de 1991. Encontrándose por los magistrados de la época, que su decisión encontraba soporte en el derecho a la igualdad, sin que dejase de ser una decisión restringida para las necesidades de los pacientes, empero este fue el inicio de una serie de pronunciamientos en los cuales la Corte iría cambiando su criterio haciéndolo cada vez más extensivo, fundamentándose en el derecho social a la salud en conexidad con el derecho fundamental a la vida, hasta llegar al amparo del derecho fundamental a la salud autónomo; de allí que se desarrolle el comportamiento de dicho precedente desde sus inicios, como se evidencia en las gráficas obtenidas:

\section{EL CASO DE LAS MUJERES GESTANTES}

\section{GRÁFICA 1.}

\section{Gráfica de la Línea Jurisprudencial (Mujeres - Gestantes)}
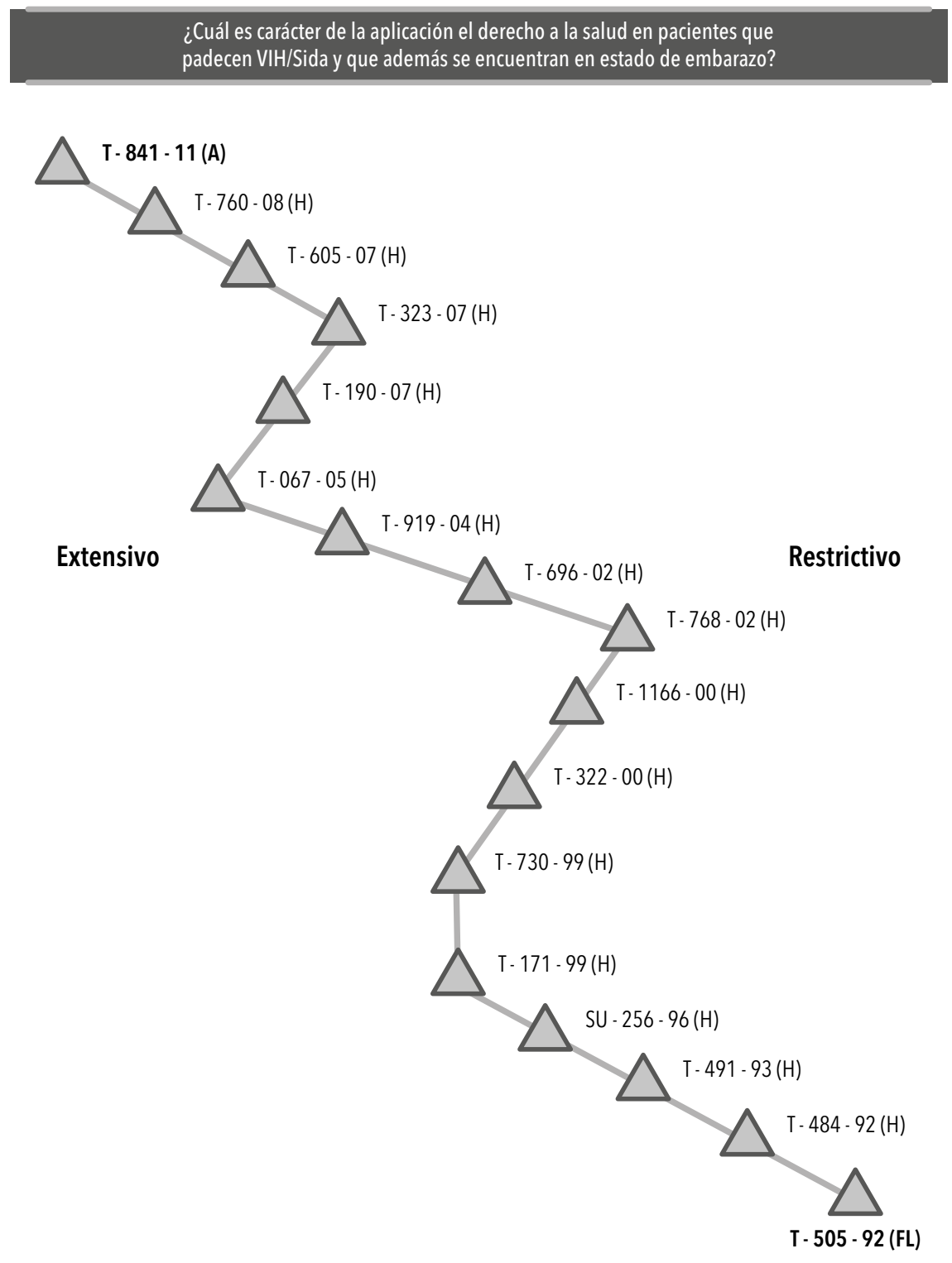

Fuente: Elaboración de la autora. 
La gráfica representa el comportamiento que han tenido los criterios de la Corte en la protección del derecho, en sentido extensivo o restrictivo, de las cuales, se encuentra la sentencia de tutela 505 de 1992 como fundadora de línea, por cuanto marcan la pauta de la protección de pacientes con VIH/SIDA, no obstante su protección se debió al amparo del derecho a la igualdad, dejando de lado el derecho a la salud y por ende, de la vida. Así en la sentencia fundadora de línea se expresa:

(...) los artículos 2 y 4 del Decreto 2591 de 1991 permiten el pronunciamiento por vía de tutela acerca de derechos no señalados expresamente por la Constitución como fundamentales. (...) el derecho fundamental de igualdad ante la Ley, es una garantía que todo individuo posee como persona humana y por lo tanto comporta tratamiento igual para todos, sistema que el Estado está en la obligación de respetar (...) el derecho que el actor pretende que se le reconozca, no encaja dentro de los lineamientos del Derecho Fundamental consagrado en el artículo 13 de la Carta Política, el infectado o enfermo de SIDA goza de iguales derechos que las demás personas (...) las autoridades están en la obligación de darles a estas personas protección especial con miras a garantizar sus derechos humanos y su dignidad (...) a prestación gratuita del servicio de salud constituye un privilegio que puede estar justificado constitucionalmente dependiendo de la finalidad o de los objetivos buscados. Esta circunstancia se presenta, entre otros casos, cuando para evitar un riesgo mayor -como sería la presencia de un evento epidemiológico-, es indispensable destinar recursos sin posibilidad de una contraprestación. (...) El derecho fundamental a la igualdad, en su modalidad de protección especial a las personas que se encuen- tran en circunstancias de debilidad manifiesta, es un derecho de aplicación inmediata. EI SIDA, como enfermedad mortal, atenta contra la vida misma. La prestación del servicio de salud al enfermo de SIDA es un imperativo que surge de la naturaleza solidaria y respetuosa de la dignidad humana que proclama y busca hacer efectivo nuestro régimen jurídico (Corte Constitucional, Sala Segunda de Revisión, Sentencia de Tutela 505, 1992).

Luego de varios pronunciamientos con este fundamento, como las sentencia T - 484 de 1992, T - 491 de 1993, SU - 256 de 1999, que con leves impulsos proteccionistas, dieron paso a la sentencia T - 171 de 1999, con la cual se pretendió otorgar la garantía del derecho a la salud por medio de la acción de tutela, fundamentada en la repercusión directa con el derecho a la vida del individuo.

(...) la naturaleza infecciosa y mortal del SIDA, requiere una prestación eficiente y oportuna de los servicios médicos, lo cual obliga a tomar medidas urgentes que garanticen el cese de la transgresión del derecho a la salud en conexidad con la vida (...) no solo en protección de sus derechos al encontrarse en condiciones de debilidad manifiesta (Art. 13 y 43 C.P), sino la protección de los derechos del menor que está por nacer. (...) El nasciturus "se encuentra protegido por el espectro de privilegios que la Carta Fundamental reserva para los niños" por lo que es titular de derechos fundamentales que pueden ser amparados a través de la acción de tutela. (...) la obligación de asistir y proteger al niño corresponde en primer lugar a la familia, luego a la sociedad y finalmente corresponde al Estado. Por consiguiente, y aún más claro en caso de enfermedades como el SIDA, es evidente que el derecho a la salud tiene tres destinatarios, a saber: el beneficiario, quien 
debe tomar las medidas universales emitidas para proporcionar el "auto-cuidado" por su propia protección y abstenerse de realizar acciones que conlleven riesgos de contagio para la sociedad. El segundo destinatario es la sociedad, a quien corresponde, en desarrollo del principio de solidaridad (C.P. Art. 1), colaborando con la eficiente y oportuna prestación de este derecho, puesto que al pagar oportunamente las contribuciones, efectuar un uso racional de los servicios y otorgar un trato humano y digno a los infectados de SIDA, se permite la efectividad del derecho a la salud de los infectados. Y, finalmente el Estado es el tercer destinatario del derecho a la salud, a quien corresponde garantizar la protección de este derecho a través de la eficiente prestación de servicios que presta de manera directa o por intermedio de particulares (C.P. Art. 49) (Corte Constitucional, Sala Séptima de Revisión, Sentencia de Tutela 171, 1999).

Posteriormente, otros fallos continuaron con la tímida postura protectora, como la T-768 de 2002 ubicada en la zona mediana de la gráfica, puesto que en sede de tutela no le otorgó la protección solicitada por la gestante respecto de su derecho a la salud, surgido a partir de la negativa de su empleador a la licencia de maternidad, puesto que el Juez Constitucional le indica que la competencia se encuentra en cabeza de la jurisdicción laboral, desamparándose sus derechos fundamentales como mujer gestante y del no nacido. Así en el 2005 distintos pronunciamientos permiten hallar una postura más extensiva, al eliminar los trámites o requisitos para la efectiva prestación del servicio salud para maternas donde se encuentre comprometida su vida, no obstante, las limitaciones continúan evidenciándose en posteriores reclamaciones de tutela, puesto que solo se aplica el anterior presupuesto bajo el imperativo del riesgo de la vida.

(...) De estar comprometida la vida del paciente, las EPS están inexcusablemente obligadas a prestar en forma inmediata los servicios de salud requeridos, sin que para ello importe su exclusión del POS, pues es inconstitucional la oponibilidad de requisitos que dilaten la prestación requerida por el enfermo de VIH/ SIDA. El Decreto 1543 de 1997, "Por el cual se reglamenta el manejo de la infección del (VIH), el (SIDA) y otras (ETS)" en el cual se consagró, en el artículo 9 , el derecho a la atención médica integral de la salud a las personas infectadas y las enfermas del VIH/ SIDA. Se dice: "Esta [la atención integral de la salud] incluirá los medicamentos requeridos para controlar la infección por el VIH y SIDA, que en el momento se consideren eficaces, para mejorar la calidad de vida de la persona infectada" ${ }^{3}$ (Corte Constitucional, Sala Octava de Revisión, Sentencia de Tutela 067, 2005).

Situación que se acentuó con algunos fallos siguientes, puesto que se presentan barreras que impiden la debida garantía por parte de la Corte en sus posturas, impidiendo la debida realización del derecho a la salud, pero a medida de los años va ampliando su rango de protección, como se observa en contraste a los pronunciamiento menos proteccionistas emanados por la Corte durante el año 2002, mientras que con la sentencia T-323 de 2007 no limita la protección integral de la materna y del no nacido, al hecho de encontrarse en peligro la vida, sino que la sola vulneración de derecho fundamentales de alguno de los dos, los hace susceptibles de la tutela inmediata, y

\footnotetext{
3 Subrayado de la autora.
} 
aún más específico, la responsabilidad por el pago de la licencia de maternidad, debido a la concurrencia de una protección doblemente reforzada.

(...) frente a reclamos de tal naturaleza existe una protección doblemente reforzada, pues concurren los derechos constitucionales del hijo y de la madre al mismo tiempo, que forman una unidad, mayor que la suma de los elementos que la integran (madre e hijo) y que por lo mismo debe protegerse como tal." (...) las madres cabeza de familia gozan de una protección constitucional reforzada, para proteger al núcleo familiar inmediato, el cual puede estar conformado por los hijos menores de edad como por personas discapacitadas que aquella tenga a su cargo. La mujer embarazada que pretenda el reconocimiento de la licencia de maternidad no tiene la obligación de cotizar por 36 semanas anteriores al parto ${ }^{4}$, pues no todos los embarazos duran la misma cantidad de tiempo, (...) la obligación de cotización será por el tiempo que dure su gestación... (Corte Constitucional, Sala Quinta de Revisión, Sentencia de Tutela $323,2007)$.

A partir de allí, la Corte no encuentra argumento para restringir la protección del derecho a la salud en esta población, debido a la importancia de garantizar este derecho en la etapa de gestación, puesto que se trata de menores en desarrollo dentro del vientre de su madre:

... el acceso a un servicio de salud debe ser continuo, ininterrumpido súbitamente; viola el derecho a la salud una EPS que suspenda el suministro de un tratamiento médico que se requiera, antes de que este haya sido efectivamente asumido por otro prestador. En especial, si se trata de un sujeto de especial protección en salud, por padecer una enfermedad catastrófica o de alto costo, caso en el cual, adicionalmente, no pueden cobrársele copagos. (...) toda persona tiene el derecho fundamental a acceder efectivamente a los servicios de salud que se requieran para enfermedades ruinosas o catastróficas, sin discriminación alguna, por lo que 'bajo ningún pretexto's se les podrá negar el acceso, por lo que el desconocimiento del principio de continuidad en este caso es aún más grave, (...) La limitación a la libertad de afiliación de las personas con en enfermedades catastróficas no debe impedir que la persona pueda acceder a los servicios de salud que requiere, con calidad, oportuna e idóneamente ... (Corte Constitucional, Sala Segunda de Revisión, Sentencia de Tutela 760,2008 ).

Y más recientemente, la sentencia seleccionada como arquimedica, es la sentencia T-841 de 2011 en la que, al reafirmar el concepto presentado por la sentencia de Constitucionalidad 355 de 2006 permitió la práctica de la IVE, se pensaría que se estaría vulnerando el derecho a la salud del nasciturus puesto que ni siquiera se le está permitiendo desarrollarse dentro del vientre de su madre, no obstante, la Corte está garantizando el derecho a la salud de la madre, en armonía común tanto de derecho relativos a la autonomía, es por ello que en dicha sentencia, se sienta una postura ampliamente proteccionista en cuanto a la salud física, psicológica y en otras áreas de la madre, que también requieren de protección cobijadas bajo este derecho.

Subrayado de la autora. 
Las mujeres cuya vida o salud física o mental está en riesgo por causa del embarazo tienen el derecho fundamental de exigir la IVE,...las EPS solo pueden exigirles un certificado médico de tal amenaza, ya que este fue el único requisito en la sentencia C-355 de 2006 (...) cualquier requisito adicional constituye incumplimiento de la obligación de respetar el derecho fundamental a la IVE (Corte Constitucional, Sala Octava de Revisión, Sentencia de Tutela 841, 2011).

\section{EL CASO DE LAS TRABAJADORAS SEXUALES}

\section{GRÁFICA 2.}

\section{Gráfica de la Línea Jurisprudencial (Trabajadoras sexuales y LGBTI)}
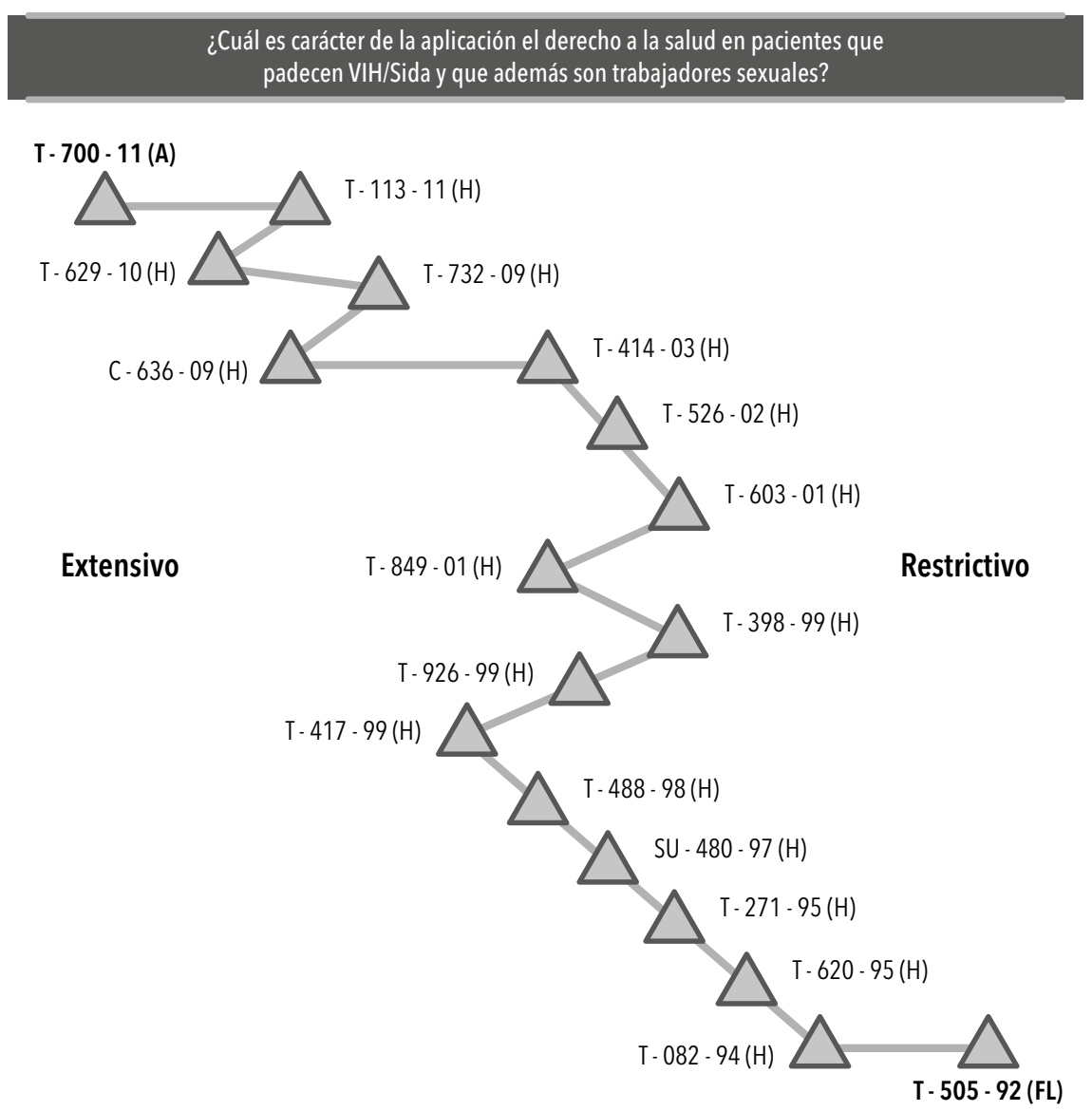

Por su parte, en cuanto a los pronunciamientos desde la Corte Constitucional en torno a la protección en materia de salud para las trabajadoras sexuales, se identifica una postura menos uniforme de la observada en la gráfica correspondiente a mujeres gestantes, en cuanto la línea trazada para las trabajadoras sexuales muestra varias desviaciones de un lado a otro de los extremos de la gráfica, esto debido a distintas posturas individuales influyentes en la ponderación de derechos, encontrándose que respecto de este grupo poblacional la garantía del derecho a la salud ha sido fuertemente desprotegido. La sentencia seleccionada como fundadora de línea es la T - 505 de 1992, (Corte Constitucional, Sala Segunda de Revisión, Sentencia de Tutela) al igual que en el grupo anterior, debido a ser este el primer fallo emitido por la Corte en el sentido de proteger a los pacientes de VIH/SIDA.

La siguiente sentencia en marcar la pauta en el criterio seguido por la Corte, es la T-082 de 1994, en la que se protege la existencia de lugares dedicados al cuidado de

Fuente: Elaboración de la autora. 
pacientes con dicha enfermedad, frente al temor de sus vecinos a ser contagiados por el solo hecho de su cercanía a sus hogares y el manejo de los residuos "hospitalarios" que provenían de dicho lugar, esto debido a inexistencia de estudios científicos internacionalmente aprobados, que permitieran indicar que la habitación cercana a un lugar de este tipo, permite el contagio, presentándose no como una sentencia que permita una amplia protección de la salud para los pacientes, sino como la primera puerta abierta para su garantía integral.

(...) por estar íntimamente relacionados con el derecho fundamental a la vida y a la integridad del actor, de su familia y de los vecinos de las casas mencionadas, (...) el manejo de las basuras, las condiciones en que se encuentran los enfermos en las casas, los tratamientos médicos que allíse realizan, y, en general, los riesgos de contagio para los vecinos. Pues, es un hecho notorio que el SIDA es una enfermedad mortal, que no existe en la actualidad ningún remedio conocido $^{6}$. Por consiguiente, es natural el temor que asalta a los vecinos, de ser contagiados, si no se están adoptando las medidas apropiadas y no se cuenta con la suficiente información al respecto. Es decir, el derecho que presuntamente se les estaría vulnerando es el de la vida (...) desde la órbita exclusivamente constitucional, al obrar prueba de que NO existe la menor posibilidad de contagio para el actor y los vecinos de las casas mencionadas, por el solo hecho de la cercanía, el juez de tutela no puede acceder a las pretensiones del actor, es decir, no puede ordenar que cesen en forma definitiva las actividades que se desarrollan en las casas, y que se trasladen los

6 Subrayado de la autora. enfermos a otros sitios. (...) por la especial naturaleza de la cuestión de que se trata, la decisión de no conceder la tutela, eventualmente podría ser diferente, si sobreviniera un cambio, $y$, como resultado de las investigaciones que a nivel mundial se llevan a cabo sobre el SIDA, se estableciera que dicha cercanía puede ofrecer peligro de contagio. Es decir, la presente sentencia constituye uno de aquellos casos en los que la cosa juzgada es relativa, porque la decisión está determinada por las circunstancias (Corte Constitucional, Sala Primera de Revisión, Sentencia de Tutela 082, 1994).

Para los años siguientes, la Corte continúa sentando algunas pautas en la protección de dicha población, no obstante se presenta muy restringido y demorado el desarrollo proteccionista, puesto que avanza poco, imponiendo siempre el riesgo por la vida, dejando sin protección a muchos tutelantes, sin embargo, da respaldo a tratamientos alternativos por vía de tutela.

El derecho a la salud y a la seguridad social son derechos prestacionales propiamente dichos, que para su efectividad requieren normas presupuestales, procedimiento y organización, que viabilizan y optimizan la eficacia del servicio público y que sirven además para mantener el equilibrio del sistema. Son protegidos, como derechos fundamentales si está de por medio la vida de quien solicita la tutela. (...) ordena que se suministre a los enfermos del sida los antiretrovirales que el médico tratante indique. Solo se pueden recetar medicamentos que tengan registro sanitario en Colombia, con presentación genérica, a menos que solo existan los de marca registrada. (...) el enfermo es autónomo para aceptarlos o no, y si los acepta, tiene derecho a la entrega de la droga por la EPS, con la condición de que sea recetada por el médico tratante. La importancia de los grupos de apoyo, 
en el tratamiento del SIDA, genéricamente es reconocida. Lo prudente es no obstaculizar el funcionamiento de las asociaciones comunitarias conformadas por los portadores del SIDA y sus familiares. Si el tema se plantea bajo el aspecto de terapia, es indispensable que haya prueba de que el funcionamiento de los grupos no afecta la terapia sino que la complementa, porque el juez de tutela no puede dar una orden de tratamiento no señalada por los galenos que orientan la curación del paciente. (...) lo que interesa es la garantía del "acceso a los servicios de promoción, protección y recuperación de la salud" (Art. 49 C.P.). (Subraya fuera de texto) (Corte Constitucional, Sala de Revisión, Sentencia de Unificación 480, 1997).

Luego se extiende un poco el criterio, en cuanto quita obstáculos en el acceso a la salud, como las normas de cotización mínima, puesto que limitan la realización del derecho, no obstante, mantiene las circunstancias por las cuales se accede a las peticiones por vía de tutela.

La aplicación indiscriminada de las normas que exigen tiempo mínimo de cotización, vulnera el derecho constitucional a la salud, en conexión con los derechos fundamentales a la vida y a la integridad física, de quien necesita el tratamiento cuando: 1. La falta del tratamiento vulnera o amenaza los derechos a la vida y a la integridad física; 2 . El tratamiento no pueda ser sustituido por otro no sometido a semanas mínimas de cotización; 3. El interesado no pueda cubrir el porcentaje que la E.P.S. se encuentra autorizada legalmente a cobrar y no pueda acceder al tratamiento por otro plan distinto que lo beneficie y 4. El tratamiento haya sido prescrito por un médico adscrito a la E.P.S.

Subrayado de la autora. de quien se está solicitando el tratamiento. Teniendo en cuenta que, el VIH es una enfermedad que requiere tratamiento inmediato, so pena de la agravación de sus efectos sobre el paciente, es claro que la aplicación estricta de la legislación que somete a un período mínimo de cotizaciones al sistema, el cubrimiento por el POS de los medicamentos requeridos en este caso, amenaza los derechos a la vida, a la dignidad humana y a la salud del peticionario ${ }^{8}$, quien, por no poder sufragar directamente los costos de esos medicamentos, se ve abocado a cotizar las semanas que le faltan (50), es decir, casi un año para acceder al tratamiento que reduce los graves efectos del VIH en su organismo... (Corte Constitucional, Sala Sexta de Revisión, Sentencia de Tutela 417, 1999)

Mientras que en los años siguientes, la Corte es enfática en sustraer de responsabilidad a las entidades prestadoras de la salud cuando de estas no dependiera otorgar la garantía del derecho a la salud de quien lo necesitase, sin que surgiera del mismo pronunciamiento la obligatoriedad de políticas preventivas que permitieran el cubrimiento total de acceso en salud.

(...) no existe vulneración del derecho a la salud, cuando no haya negligencia o ineptitud del accionado, como por ejemplo, se gestionen actividades inter institucionales para la obtención de la práctica de los exámenes que requiera el paciente, como la solicitud por escrito a la I.P.S. la práctica del examen, sin embargo, cuando ocurran imprevistos fuera de la voluntad de las entidades, no hay responsabilidad en estas, más que asesorar al paciente para que acuda a la Secretaría de Salud, solicitando la realización de los exámenes, con cargo a los recursos de oferta. (...) 
[Las instituciones] estaban en la obligación de atenderlo, la solución era informarle a la peticionaria que debía acudir a la Secretaría de Salud de Bogotá para solicitar que le asignaran el centro hospitalario en el cual le practicaran el examen requerido. La prueba de "Genotípica de Resistencia al VIH" si resulta determinante para la salud y la vida de los pacientes de $\mathrm{VIH} /$ Sida ${ }^{9}$, porque de esta depende el incremento de la carga de medicamentos efectivos para el paciente, por lo tanto, debe ser practicada porque de ella pende la evolución de la enfermedad y la salud (Subraya fuera de texto) (Corte Constitucional, Sala Novena de Revisión, Sentencia de Tutela 603, 2001).

Ahora bien, al tratarse específicamente sobre las trabajadoras sexuales, en 2009 un fallo de constitucionalidad sentó puntualmente un importante precedente en la extensión proteccionista de la Corte, al determinar la obligatoriedad del amparo al derecho a la salud, pero a su vez se abstuvo en dicho pronunciamiento de referirse a las garantías prestacionales por el desarrollo de esta actividad laboral en el entendido de las circunstancias especiales de la misma, dando lugar a percepciones de discriminación en su trato, por cuanto en su contenido no expresa la garantía plena de sus derechos frente a los de cualquier otro ciudadano. En conclusión, en el fundamento del fallo constitucional se evidencia una fallida búsqueda de norma prohibitiva de su labor, por lo que se remite al texto constitucional al rechazar indirectamente la práctica de tal actividad.

(...) Aunque del régimen constitucional colombiano no se deriva una prohibición al ejercicio de la prostitu- ción, el Estado no es indiferente a sus efectos nocivos, por lo que resulta legítimo, dentro de los límites razonables de la proporcionalidad, que las autoridades públicas de todos los órdenes adopten medidas tendientes a evitar su propagación y a disminuir los efectos negativos que esta conducta, calificada como degradante para la persona humana, genera en la sociedad. (...) las limitantes a este derecho vienen de la misma Carta Fundamental, en la que se concilian los intereses individuales con los colectivos. "al tenor del artículo 95 de la Carta, el primer deber de toda persona consiste en respetar los derechos ajenos y no abusar de los propios (art. 95, núm. 1). Y el artículo 49 superior, inciso final, impone a toda persona "el deber de procurar el cuidado integral de su salud y la de su comunidad"10 (Corte Constitucional, Sala Plena, Sentencia de Constitucionalidad 636, 2009).

Sin embargo, otros fallos resaltan la especial trascendencia que conlleva la salvaguarda a la mujer como ser capaz de gestar la vida, pero al mismo tiempo de autodeterminación, en cuanto deben garantizársele el acceso a los servicios de salud, incluidos aquellos preventivos, paliativos y pos patológicos, circunstancia que no puede ser desconocida para las trabajadoras sexuales, puesto que dicha garantía se enfoca especialmente al área sexual y reproductiva.

(...) Los derechos reproductivos reconocen, respetan y garantizan la facultad de las personas, en especial a las mujeres, de acceder a servicios de salud reproductiva. Estos incluyen, entre otros: (...) Medidas que garanticen una maternidad libre de riesgos en los periodos de gestación, parto y lactancia y que brinden 
las máximas posibilidades de tener hijos sanos. los derechos sexuales reconocen, respetan y protegen (i) la libertad sexual y (ii) el acceso a los servicios de salud sexual y por ello, las personas tienen derecho a decidir autónomamente tener o no relaciones sexuales y con quién (Artículo 16 de la Constitución). En otras palabras, el ámbito de la sexualidad debe estar libre de todo tipo de discriminación, violencia física o psíquica, abuso, agresión o coerción, de esta forma se proscriben, por ejemplo, la violencia sexual, la esclavitud sexual, la prostitución forzada. De igual forma, los derechos sexuales reconocen, respetan $y$ garantizan la facultad de las personas de acceder a servicios de salud sexual $^{11}$, los cuales deben incluir, básicamente: (i) Información y educación sobre todos los aspectos de la sexualidad, (ii) El acceso a servicios de salud sexual de calidad para atender y prevenir las infecciones, dolencias y enfermedades que afecten el ejercicio de la sexualidad y (iii) Educación e información sobre los métodos anticonceptivos y acceso a los mismos (Corte Constitucional, Sala Octava de Revisión, Sentencia de Tutela 732, 2009).

Criterio extensivo por el cual se les otorga relevancia a los derechos sexuales y reproductivos, los primeros tendientes a la información y educación, la prevención y atención de infecciones, dolencias y enfermedades de transmisión sexual, así como a la anticoncepción, y solo de los reproductivos; todos estos, derechos dirigidos en igualdad de condiciones a las trabajadoras sexuales. Este presupuesto se mantuvo y se reforzó con el pronunciamiento de la Corte, en el que dio por terminado el debate sobre la definición de si la actividad desempañada por este grupo poblacional podría constituir relación laboral y por ende, acreedoras de los derechos prestacionales -incluidos los de salud- inherentes a trabajadores en cualquier otra área laboral, decisión que vale la pena textualizar:

(...) Habrá contrato de trabajo cuando él o la trabajadora sexual ha actuado bajo plena capacidad y voluntad, cuando no hay inducción ninguna a la prostitución, cuando las prestaciones sexuales y demás del servicio, se desarrollen bajo condiciones de dignidad y libertad para el trabajador y por supuesto cuando exista subordinación limitada por el carácter de la prestación, continuidad y pago de una remuneración previamente definida. Con lo cual, se pretende proteger a quienes se ganan la vida y cumplen con su derecho/deber al trabajo a través de la prostitución ejercida no de modo independiente sino al servicio de un establecimiento de comercio dedicado a ello. No existe disposición que autorice una discriminación negativa para las personas que ejercen la prostitución. (...)

De allí el imperativo constitucional de reconocer sus mínimas garantías, de permitirles ser vinculados no solo a un sistema policivo de protección en salubridad y cuidado propio, sino también al sistema universal de seguridad social, a poder percibir prestaciones sociales así como el ahorro para la jubilación y las cesantías. (...) a falta de regulación concreta, y de la mano de la construcción normativa que ordena la prostitución en Colombia, mientras la prostitución se desenvuelva bajo la modalidad del "contrato realidad", esta situación merecerá, la más decidida protección por parte del Derecho para que sean cubiertas todas las obligaciones no pagadas por el empleador durante el tiempo en que hubiese tenido lugar la relación de trabajo.

\footnotetext{
11 Subrayado de la autora.
} 
Por un lado, una decisión que aunque no resulte graciosa a los criterios de moralidad preexistentes, evita dejar en el abandono ilegítimo a las y los trabajadores sexuales como sujetos en condiciones de vulnerabilidad manifiesta, merecedores de especial protección. Pero por otro, una restricción de las garantías del trabajo, con lo que se procura evitar que el Estado, a partir de la administración de justicia, aliente el ejercicio de un oficio que, según los valores de la cultura constitucional, no es ni encomiable ni promovible. Su condición de prostituta y el plantearse como trabajadora en tal oficio, la ubica en un grupo discriminado históricamente, que por lo mismo la hace merecedora del status jurídico iusfundamental de sujeto de especial protección por parte del Estado. (...) un despido acredita la existencia de una violación de derechos fundamentales al trabajo, la seguridad social, la igualdad, la dignidad, la protección de la mujer en estado de embarazo, el derecho del que está por nacer, el fuero materno y el mínimo vital. Al ser la prostitución una actividad cuyo ejercicio no está prohibido, ni para quien la ejerce, ni para quien tiene un establecimiento de comercio dedicado a ella, están llamados las autoridades a desplegar actuaciones que protejan los derechos de quienes ejercen la prostitución ${ }^{12}$, no solo para cuidar de su salud y abrir sus perspectivas de desarroIlo, sino también, para asegurar las garantías laborales que en el caso de trabajar por cuenta ajena merecen (Corte Constitucional, Sala Tercera de Revisión, Sentencia de Tutela 629, 2010).

Así las cosas, no hay lugar a dudas que las mujeres que desarrollan su actividad laboral como trabajadoras sexuales han sido reconocidas, a luz de la Constitución Política de Colombia, como individuos a las que por ninguna condición o circunstancia inherente a su actividad se les puede dejar de garantizar integralmente los derechos fundamentales que por derecho propio han adquirido, tratándose especialmente de la Salud.

La salud como derecho y como servicio, contemplado en el Artículo 49 Superior, tiene una doble connotación del cual la Corte ha precisado que todas las personas deben tener acceso a él, siendo tarea del Estado organizar, dirigir, reglamentar y garantizar su prestación. De manera que, el mismo fue considerado un derecho prestacional y su amparo por vía de tutela dependía de su vínculo con un derecho catalogado como fundamental - tesis de la conexidad -, generalmente tutelado con el de la vida, la dignidad humana o la integridad personal (Corte Constitucional, Sala Séptima de Revisión, Sentencia de Tutela 161, 2013).

Concepto que fue consolidado con diversos pronunciamientos en los primeros años de existencia de la Corte Constitucional, hasta su expresa definición con la sentencia de tutela 760 (2008), referida anteriormente, junto a otros fallos previos, como la sentencia de tutela 420 (2007), en los que se determinó específicamente sobre "la fundamentalidad del derecho a la salud en lo que respecta a un ámbito básico, el cual coincide con los servicios contemplados por la Constitución, el bloque de constitucionalidad, la Ley y los planes obligatorios de salud, con las extensiones necesarias para proteger una vida digna.", de allí que en la actualidad este derecho sea susceptible de ser solicitado en amparo directo por medio de la Acción de Tutela del Artículo 86 Superior.

12 Subrayado de la autora. 
En el artículo señalado anteriormente, la Corte Constitucional establece definitivamente su fundamentalidad autónoma e independiente de cualquier otro derecho, puesto que al definir los contenidos precisos del derecho a la salud, se dieron cuenta que era fundamental, generando un derecho subjetivo a favor de los beneficiarios del sistema de salud, de allí que cuando las entidades prestadoras de los servicios de salud, se niegan a suministrar tratamientos, medicamentos o procedimientos incluidos en el POS o POS-S, vulneran el derecho a la salud, el cual como se ha reiterado adquiere la condición de derecho fundamental autónomo y este puede ser protegido por la acción de tutela. (Corte Constitucional, Sala Séptima de Revisión, Sentencia de Tutela 161, 2013).

\section{CONCLUSIÓN}

La selección de la jurisprudencia ha demostrado que en el lapso de tiempo de producción jurisprudencial constitucional, han sido diferentes posturas en cuanto a los alcances del derecho a la salud, pero que en pocas ocasiones se ha pronunciado en específico frente a la población con VIH/SIDA. No obstante, el criterio de la Corte siempre ha tendido a la extensión del alcance del derecho a la salud, en especial de las poblaciones en condiciones especiales de vulnerabilidad, incluyendo a los menores e incluso los nasciturus, al cual se le reconocen no solo derechos en el Artículo 91 al referirse de la protección al que está por nacer y demás articulado en torno a la mujer embarazada dentro del Código Civil Colombiano, sino que jurisprudencialmente se les ha otorgado mayor amparo al determinarse que adicionalmente debe otorgárseles tratamiento como si se tratara de los derechos de un niño.

El grupo social de enfoque ha sido víctima de diferentes modalidades de violaciones de su derecho a la salud, la práctica más común es la imposición de trámites administrativos que obstaculizan el acceso al servicio, la Corte ha hecho análisis de las acciones aún a pesar de la muerte de la persona cuyo derecho se reclama, pues en muchas ocasiones durante el trámite de las acciones de instancia y revisión el paciente fallece, en esos casos el análisis que se hace en virtud de la función de pedagogía constitucional.

La Corte también ha aclarado que aquellas personas a quienes la Constitución Política les ha conferido una protección especial por encontrarse en circunstancias 
especiales de indefensión, su derecho a la salud es reforzado, lo que implica que su alcance se amplía y que el Estado debe diseñar políticas para que estas personas accedan de manera efectiva a toda la atención que su patología especial requiere, presupuesto aplicable a todos aquellos grupos poblacionales que en condiciones especiales de vulnerabilidad que se vean en la necesidad de solicitar amparo de su derecho a la salud, primordialmente tratándose de enfermedades catastróficas o de alto costo, como lo es el VIH/Sida, que debido a sus características nefastas en la persona y elevado valor pecuniario de los tratamientos paliativos, hacen que especialmente las personas que la padecen, aunado a sus condiciones socioeconómicas, no obtengan a satisfacción el disfrute de su derecho a la salud.

Por tal razón, la investigación "Criterios Jurisprudenciales de la Corte Constitucional para la protección del derecho a la salud en mujeres en condiciones especiales de vulnerabilidad. Caso: Gestantes y Trabajadoras Sexuales" encontró que la tendencia de la Corte en la protección de los servicios de salud para las mujeres gestantes y trabajadoras sexuales es extensiva por cuanto su evolución tiende a cubrir más aspectos relacionados con este segmento de población en condición especial de vulnerabilidad. Para citar un ejemplo, se conoció que inicialmente la Corte sí admitió tratamientos paliativos y de protección retroviral pero a medida que pasó el tiempo fueron siendo incluidos aspectos atinentes a la alimentación, transporte, cesáreas, alimentación para neonatos, la salud preventiva para la madre y salud preventiva y reproductiva para trabajadoras sexuales, entre otras.
Una segunda conclusión es que no existe fundamento normativo que haya sido aplicado jurisprudencialmente, o criterio de la Corte que permita a las entidades prestadoras de salud o a los jueces constitucionales, aplicar de manera diferenciada en los grupos poblacionales seleccionados, los diferentes elementos que comprenden el derecho a la salud; es decir que a pesar de la existencia de barreras normativas y administrativas que impiden el acceso al derecho a la salud en las condiciones adecuadas, no existe óbice para sostener la negativa de prestar los servicios de salud a cualquier persona que lo necesite, presupuesto que debe ser desarrollado y aplicado más ampliamente por las diferentes ramas del poder público en lo de su competencia.

Muchos son los ideales y metas propuestas en la garantía de los derechos fundamentales, más aún el de la salud que compromete la vida, integridad y dignidad de la persona, pero largo es el tramo hasta alcanzarlos, primero en la conciencia y luego fácticamente en la realidad colombiana.

Con ello, se observa que los criterios jurisprudenciales empleados en la fundamentación de los fallos de revisión en sede de tutela por la Corte, los cuales han evolucionado a una reforzada protección de la mujer como sujeto especial de derechos ampliamente salvaguardado en el ámbito internacional y asimismo nacional, en su condición de gestora de vida y capacidades que exceden las ya demostradas por el género masculino, es por esto que, encontrarse en su faceta de madre adquiere una especialísima protección, doblemente reforzada puesto que no solo se trata de 
la persona gestante sino de la gestada, puesto que aunque en Colombia la condición de persona esté determinada en el desprendimiento del feto del cordón umbilical de su madre y respire por sí mismo, no implica ello que el derecho a la salud de un ser humano en etapa de gestación no pueda solicitar el amparo de su derecho a la salud por el intermedio de su madre, derecho que le asiste de acuerdo con las normas nacionales e internacionales en protección del que está por nacer, en las mismas calidades establecidas para la niñez colombiana.

Por su parte, las mujeres que se desempeñan como trabajadoras de su propio cuerpo en el mercado sexual, no pueden ser objeto de discriminación; la misma Corte aunque en sus inicios se mostró reacia a garantizar los derechos de esta población con criterios de la intervención estatal en las decisiones perjudiciales para la persona y en la sociedad, recientemente ha sostenido en la jurisprudencia constitucional que no puede el Estado tomarse atribuciones en la conciencia de la persona, aun cuando es la misma Constitución la que establece el derecho de toda persona de elegir su profesión u oficio, por lo cual ningún tipo de prejuicio moral puede entrar a fundamentar alguna clase de discriminación, de allí que se predique que la salud para las trabajadoras sexuales deba ser en igualdad de condiciones a cualquier otro ciudadano, aun este debe incluir un refuerzo en la promoción de la salud preventiva, en áreas de sexualidad.






\section{BiBLIOGRAFÍA}

\section{REFERENCIAS DOCUMENTALES}

López, D. E. (2001). El derecho de los Jueces. Bogotá, DC: Legis.

\section{REFERENCIAS ELECTRÓNICAS}

Organización Mundial de la Salud. (2 de mayo de 2014). Departamento de VIH/SIDA. Recuperado de http://www.who.int/hiv/topics/es/

\section{REFERENCIAS DE DOCUMENTACIÓN LEGAL}

Constitución Política de Colombia [Const.] (1991) 2da. Ed. Legis.

Congreso de la República (23 de diciembre de 1993). Por la cual se crea el sistema de seguridad social integral y se dictan otras disposiciones [Ley 100, 1993] DO: 41.148.

Congreso de la República (19 de noviembre de 1991). Por el cual se reglamenta la acción constitucional a la tutela [Decreto 2591, 1991] DO: 40.165 .

Congreso de la República. (24 de julio de 2000). Por el cual se expide el Código Penal [Ley 599, 2000] DO: 44.097.

\section{REFERENCIAS DE DOCUMENTACIÓN JURISPRUDENCIAL}

Corte Constitucional, Sala Tercera de Revisión (15 de diciembre de 1993). Sentencia de Tutela 597 Exp. T-21469 [MP Eduardo Cifuentes Muñoz].

Corte Constitucional, Sala Primera de Revisión (01 de marzo de 1994). Sentencia de Tutela 082 [MP Jorge Arango Mejía]. 
Corte Constitucional, Sala Sexta de Revisión (09 de junio de 1999). Sentencia de Tutela 417 [Martha Victoria Sáchica].

Corte Constitucional, Sala Octava de Revisión (11 de julio de 2005). Sentencia de Tutela 067 [MP Álvaro Tafur Galvis].

Corte Constitucional, Sala Quinta de Revisión (04 de mayo de 2007). Sentencia de Tutela, 323 [MP Marco Gerardo Monroy].

Corte Constitucional, Sala Segunda de Revisión (31 de julio de 2008), Sentencia de Tutela 760 [MP Manuel José Cepeda Espinoza]

Corte Constitucional, Sala Octava de Revisión (03 de noviembre de 2011). Sentencia de Tutela 841 [MP Humberto Antonio Sierra Porto]

Corte Constitucional, Sala Séptima de Revisión (26 de marzo de 2012). Sentencia de Tutela 244 [MP Jorge Ignacio Pretelt Chaljub].

Corte Constitucional, Sala Séptima de Revisión (22 de marzo de 2013). Sentencia de Tutela 161 [MP Jorge Ignacio Pretelt Chaljub].

Corte Constitucional, Sala de Revisión (25 de septiembre de 1997). Sentencia de Unificación 480 [MP Alejandro Martínez Caballero].

Corte Constitucional, Sala Segunda de Revisión (28 de agosto de 1992). Sentencia de Tutela 505 [MP Eduardo Cifuentes Muñoz].

Corte Constitucional, Sala Séptima de Revisión (17 de marzo de 1999). Sentencia de Tutela 171 [MP Alejandro Martínez].

Corte Constitucional, Sala Novena de Revisión (07 de junio de 2001). Sentencia de Tutela 603 [MP Clara Inés Vargas]. 
Corte Constitucional, Sala Plena (16 de septiembre de 2009). Sentencia de Constitucionalidad 636 [MP Mauricio Gonzáles Cuervo].

Corte Constitucional, Sala Octava de Revisión (16 de septiembre de 2009). Sentencia de Tutela 732 [MP Huberto Sierra Porto].

Corte Constitucional, Sala Tercera de Revisión (13 de agosto de 2010). Sentencia de Tutela 629 [MP Juan Carlos Henao Pérez].

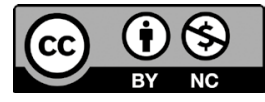

Esta obra está bajo una licencia de Creative Commons

Reconocimiento-NoComercial 4.0 Internacional 